\title{
Useful and Unique Descriptions of Tropospheric Processes Which Produce Oxygen and Thereafter Give Birth to Equatorial Electro-Jets
}

\author{
Cesar Mbane Biouele \\ Laboratory of Earth's Atmosphere Physics, Department of Physics, University of Yaoundé I, Yaoundé, Cameroun \\ Email: cesar.mbane@yahoo.fr
}

Received 18 October 2015; accepted 22 November 2015; published 25 November 2015

Copyright (C) 2015 by author and Scientific Research Publishing Inc.

This work is licensed under the Creative Commons Attribution International License (CC BY).

http://creativecommons.org/licenses/by/4.0/

(c) (1) Open Access

\section{Abstract}

Formation of negative static charges $\left(\mathrm{e}^{-}\right)$throughout troposphere is a natural phenomenon revealed by some weather events such as storms and lightning flashes that accompany thunderclouds. This climatic phenomenon (formation of negative charge in that case) has long been considered as physical phenomena of very small space-time scales. Now we have good reasons to say that this perception of troposphere electrical status is totally meaningless. Indeed, it is now easy to show that significant numbers of electrons are provided to troposphere at each appearance of a thunderstorm (or a lightning flash). Thereafter, movement implemented in the troposphere by winds (e.g., West African aerojet) contributes to the formation of low altitudes Electrojets (e.g., West African Equatorial Aerojet gives birth to West African Equatorial Electrojet). The existence of Low Layers Equatorial Electrojets (LL-EE) was totally unknown by the first theorists who have studied the Earth's Ionosphere Plasma Physics and Electrodynamics. This mistake has led their followers to many questions unanswered in their attempt to explain the longitudinal and seasonal variations of observed EEJ. In this paper, we will provide many useful explanations on the manner in which clouds provide oxygen to troposphere and thereafter trigger negative static charges $\left(\mathrm{e}^{-}\right)$ throughout both troposphere and ionosphere. Indeed, this paper also explains how, opportunely, the ITF (inter tropical front) plays the role of the tap which facilitates oxygen transfer from troposphere to ionosphere. Detailed studies on the Earth's troposphere plasma physics and electrodynamics are impatiently awaited.

\section{Keywords}

Formation of Negative Static Charges ( $\mathrm{e}^{-}$) throughout Troposphere, Earth's Troposphere Plasma Physics and Electrodynamics, Oxygen Transfer from Troposphere to Ionosphere 


\section{Introduction}

Formations of negative static charges $\left(\mathrm{e}^{-}\right)$throughout troposphere are natural phenomena revealed by some weather events such as storms and lightning flashes that accompany thunderclouds. These meteorological phenomena (formation of negative charge in that case) have long been considered as events limited in time (i.e., transient process) and space (i.e., isolated process). Now we have good reasons to say that this perception of troposphere electrical status was totally meaningless. Indeed, it is now easy [1]-[4] to show that thunderstorms provide significant numbers of electrons to troposphere at each of their (thunderstorms in this case) appearance. Thereafter, movement implemented in the troposphere by Rossby waves (e.g., West African aerojet) contributes to the formation of low altitudes Electrojets (e.g., West African Equatorial Aerojet gives birth to West African Equatorial Electrojet). Until today, the existence of low layers Equatorial Electrojets (LL-EEJ) was totally ignored by researchers [5]-[22] who use space or ground base data to study Ionosphere's Equatorial Electrojet (EEJ) and this has led many of them to errors, in their attempt to explain the longitudinal and seasonal variations of observed EEJ. In this paper, we are going to give very useful and unique explanations on the manner in which clouds provide oxygen to troposphere and thereafter trigger negative static charges $\left(\mathrm{e}^{-}\right)$throughout both troposphere and ionosphere. Indeed, this paper will also explain how, opportunely, the ITF (inter tropical front) plays the role of the tap which provides oxygen to ionosphere: which oxygen thereafter triggers ionospheres' Equatorial Electrojet (EEJ).

\section{Processes That Provide Oxygen and Static Negatives Charges ( $\left.\mathrm{e}^{-}\right)$to Troposphere}

In the past, researchers have often mentioned the presence of condensation nuclei in the atmosphere to trigger the fall of water droplets (solid or liquid) contained in the clouds. This concept (very popular in the 18th century) has not been sufficiently exploited and this led to an erroneous definition of the cloud. In a very recent work [2], we define the cloud as a gas formed by dry air and saturated water vapor. Misperception of the processes responsible for the formation of clouds has long moved away researchers from the true nature of weather's processes behind the formation of precipitation. These weather's processes are closely related to the management of irradiative energy or latent and sensible heat flux (Figure 1).

\subsection{Condensation of Saturated Water Vapor}

Very recent studies [3] [4] on the physics of clouds show that condensation is the thermodynamic process in which saturated water vapor fixes carbon atom to form water droplets (solid or liquid) and releases oxygen (Figure 2).

\subsection{Electrification of Water Droplets' Carbonates Atoms}

Due to winds' stress, droplets’ carbonates atoms provide both electrical negative static charges ( $\mathrm{e}^{-}$) and positive static charges $\left(\mathrm{C}^{4+}\right)$ to troposphere (Figure 3).

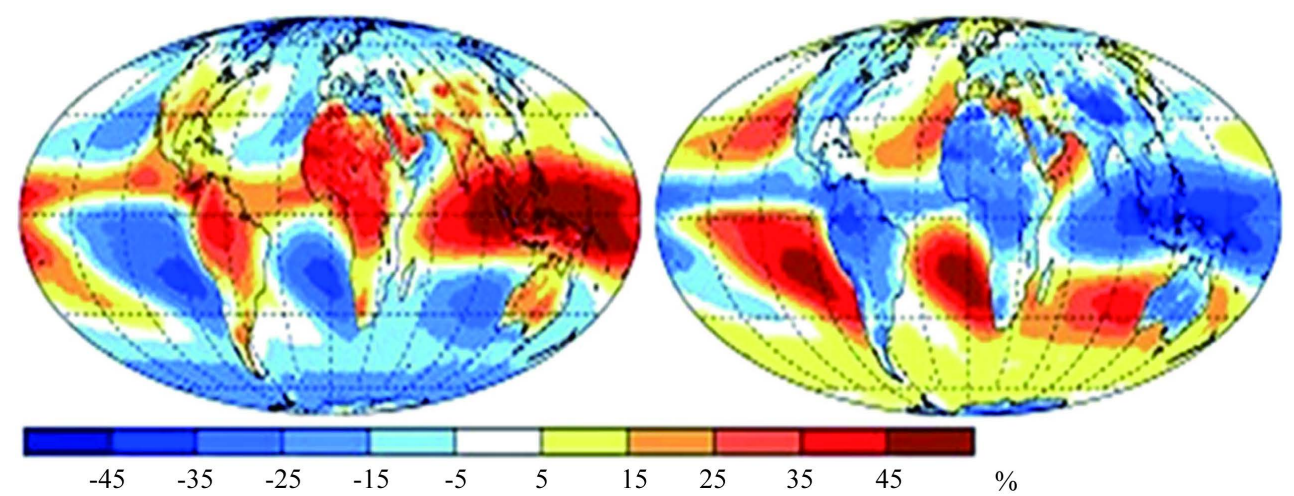

Figure 1. Regional variations in the coverage of high clouds (left) and low clouds (right) compared to the total annual average (in \%), statistic of climatology covering 2003-2009. 

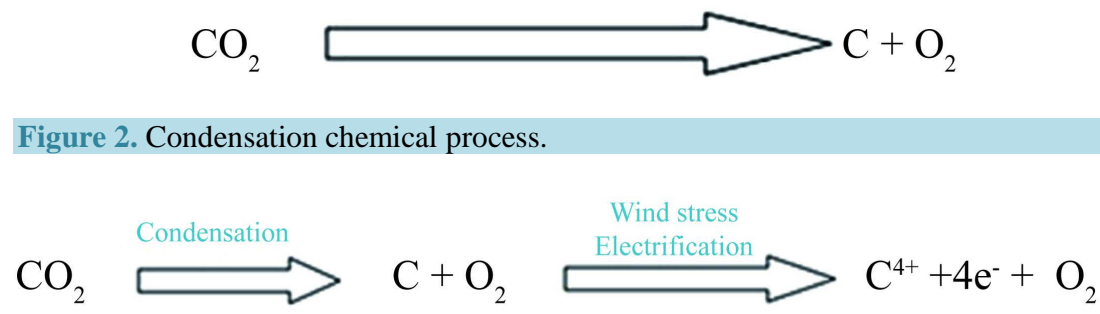

Figure 3. Tropospheric processes which provide Oxygen and thereafter electrons.

N.B.: the carbon ion $\mathrm{C}^{4+}$ (diluted in rain or snow droplets) join ground's surface under the influence of gravity or lightning flashes. Oxygen and some of electrons released from carbon ions remain in the troposphere after storms which give birth to them. In other words: each rain provides a significant amount of oxygen $\left(\mathrm{O}_{2}\right)$ and electron ( $\mathrm{e}^{-}$) to Troposphere. Appearance of frequent and heavy rains means higher electrification of the Troposphere: electrical status of the Troposphere depends mainly on regional variations in the coverage of high clouds and low clouds (Figure 1) and (this is an important remark) on the regional coverage of dioxide Carbon $\left(\mathrm{CO}_{2}\right)$ emissions.

\section{Processes That Provide Oxygen and Static Negatives Charges ( $\left.\mathrm{e}^{-}\right)$to Ionosphere}

\subsection{Processes That Provide Oxygen to Ionosphere}

Since troposphere is a medium in which mass motions are easily started, convection is found to be one of the chief ways in which heat is transferred there. This transfer may be accomplishing either by vertical or by horizontal motions (Figure 4(a)). Tropopause is a layer where the sign of vertical gradient of temperature change. This layer is a hermetic barrier for daily representation of general circulation or ITF (Inter tropical front) vertical motion (Figure 4(a)). Everyone must now remember that Tropopause is not a hermetic barrier for the instant representation of the atmosphere general circulation. That is why, opportunely, the ITF (inter tropical front) plays the role of the tape which facilitates oxygen transfer from Troposphere to Ionosphere (Figure 4(b)).

\subsection{Processes That Provide Electron to Ionosphere}

UV-rays provided by the sun act on oxygen $\left(\mathrm{O}_{2}\right)$ and trigger electrical positive $\left(\mathrm{O}^{+}\right)$and negative $\left(\mathrm{e}^{-}\right)$static charges (Figure 5).

\section{New and Unique Definition of Total Electrons Content (TEC)}

According to relevant explanations of our study, researchers must next time considered electrons which exist in Troposphere. New and unique description of TEC is now available to make this important correction (Figure 6) and better understand the based and observed EEJ. Taking in account the fact that electrical status of the Troposphere depends mainly on regional variations in the coverage of high clouds and low clouds (Figure 1) and (this is an important remark) on the regional coverage of dioxide Carbon $\left(\mathrm{CO}_{2}\right)$ emissions, EEJ longitudinal and seasonal variation will now be clearly explained.

\section{Conclusion}

This study opens new research avenues. Moreover, rains provide oxygen and thereafter electrons both to troposphere and ionosphere. Each thunder (or lightning flash) formally highlights the presence of significant numbers of electrons in the troposphere. It is therefore wrong to think that lightning flashes, which are clear evidence of the formation of recombination currents, can completely eliminate all negative charges that have allowed their appearances within the troposphere. New and unique descriptions of TEC are now available and must lead to important corrections and accurate interpretations of the based and observed EEJ. Taking into account the fact that electrical status of the troposphere depends mainly on regional variations in the coverage of high clouds and low clouds (Figure 1) and (this is an important remark) on the regional coverage of dioxide Carbon $\left(\mathrm{CO}_{2}\right)$ emissions, EEJ longitudinal and seasonal variations are closely parallel to ITF (Inter Tropical Front) summers' and winters' extremes (Figure 7(a), Figure 7(b)). 

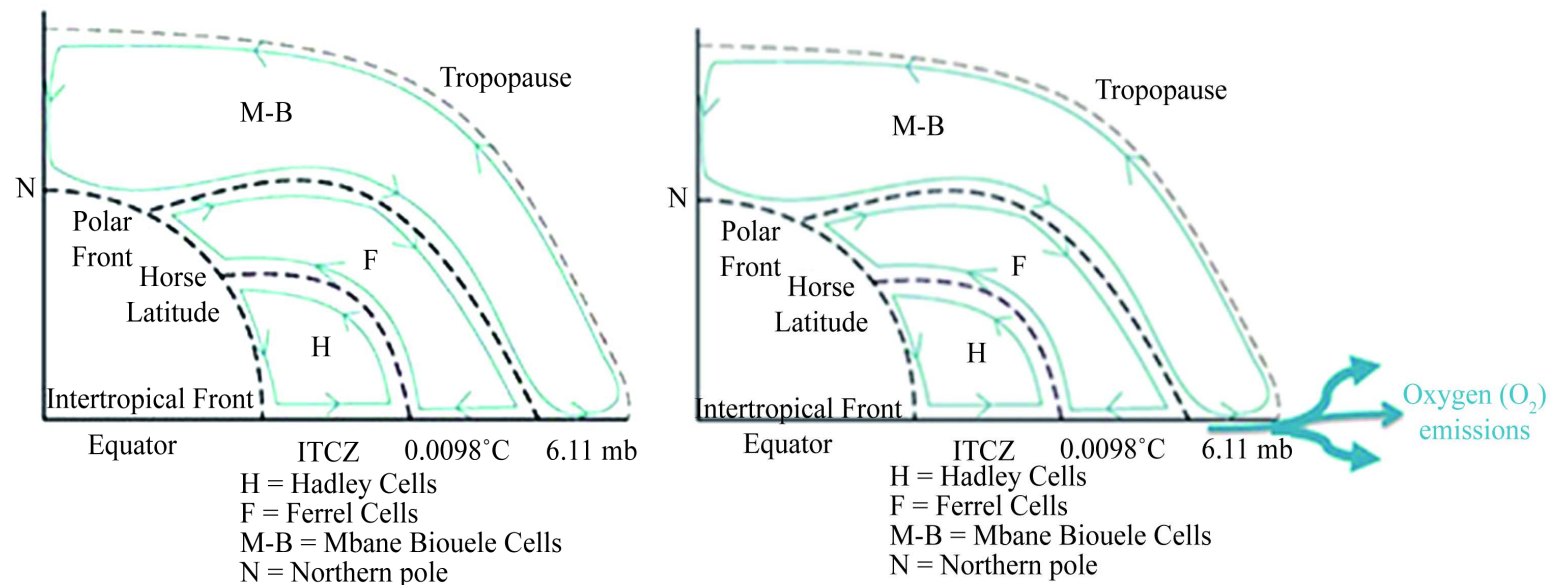

Figure 4. (a) Unique and faithful representation of Earth's atmosphere general circulation [2] [3]; (b) Unique representation of oxygen transfer from troposphere to higher altitude layers. N.B.: There is no known process able to produce oxygen in the Ionosphere. That is why we have no doubt that Troposphere is the unique atmosphere layer which provide oxygen to Ionosphere as shown in Figure 4(b).

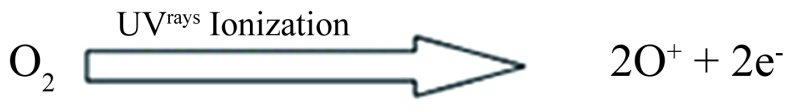

Figure 5. Processus that provide electrons to ionosphere. N.B.: due to electron high mobility, 02 plasma domains occurred in Ionosphere. EEJ is located in plasma bulbe formed by electrons.

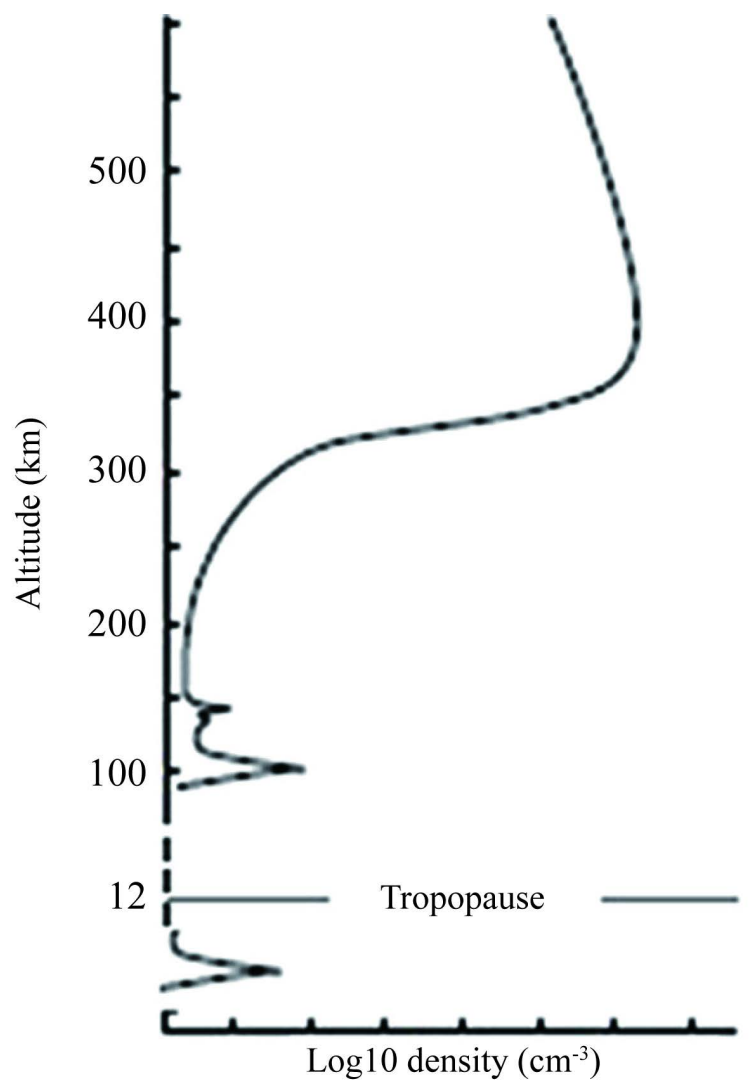

Figure 6. Unique and useful representation of vertical profile of Earth's atmosphere total electrons content (TEC). 


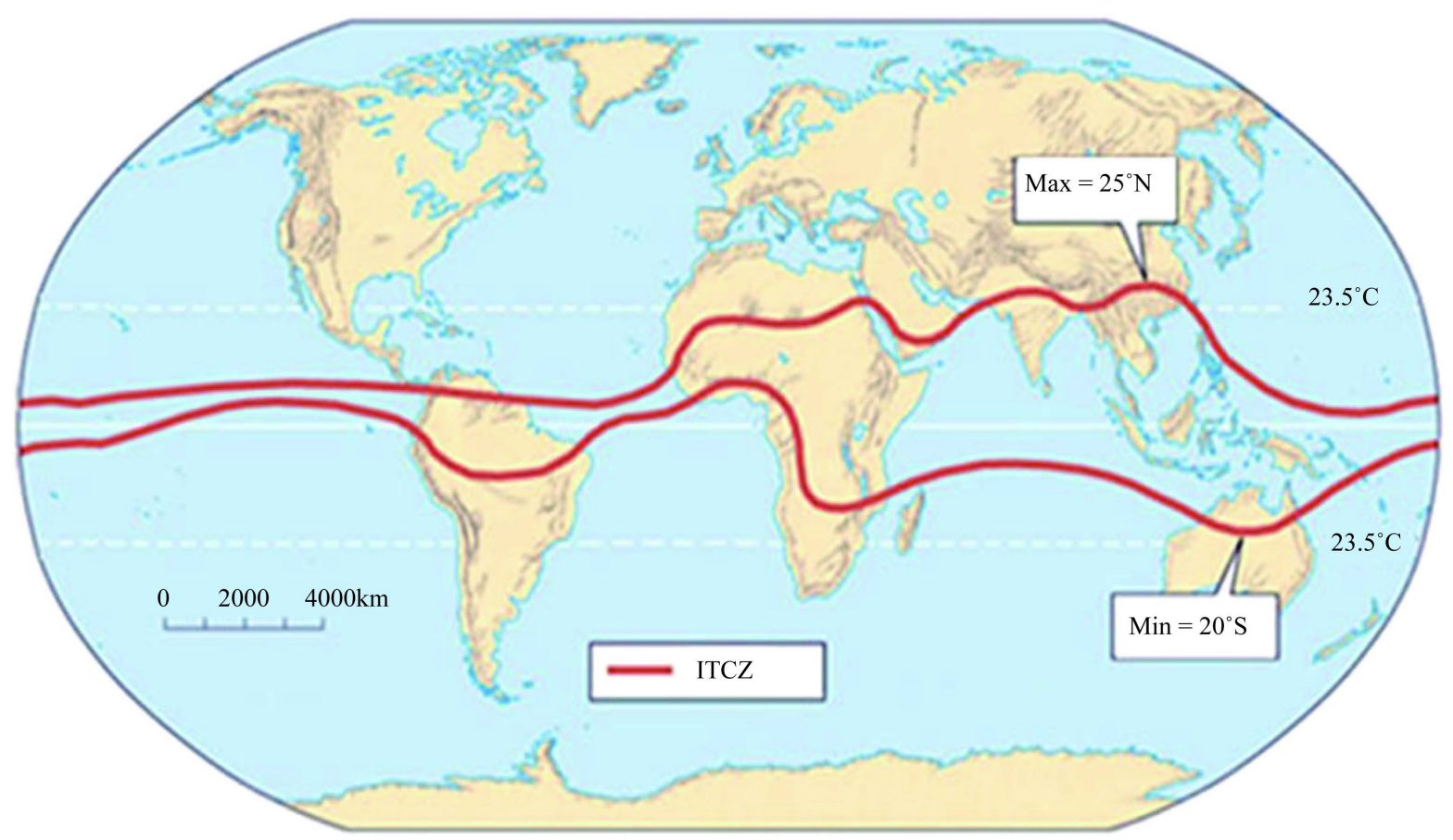

(a)

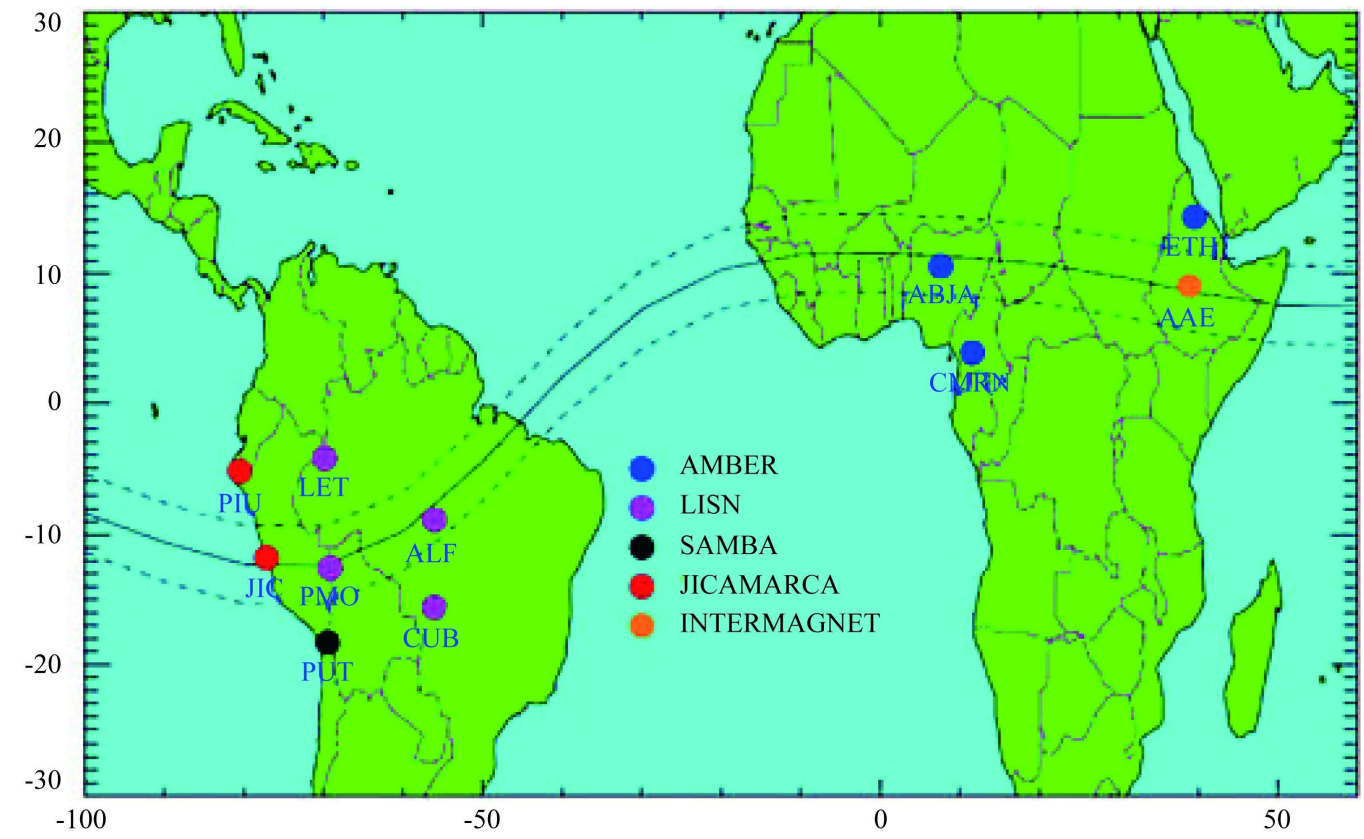

(b)

Figure 7. (a) ITF (Inter Tropical Front) summers' and winters' extremes (red lines); (b) EEJ (Equatorial Electrojet) extremes.

\section{Acknowledgements}

For their truthful and fruitful interest to space weather sciences, the author wants to acknowledge:

- Endawoke Yizengaw, Boston College, USA.

- Patricia Doherty, Boston College, USA.

- Amory Mazaudier Christine, France. 
- Babatunde Rabiu, Nigeria.

- Vafi Ndoumbia, Ivory Coast.

- Obrou Olivier, Ivory Coast.

\section{References}

[1] Mbane Biouele, C. (2015) Fundamentals on Thermodynamic Processes behind Cloud's and Rainfall's Formation. Atmospheric and Climate Sciences, 5, 257-265. http://dx.doi.org/10.4236/acs.2015.53019

[2] Mbane Biouele, C. (2015) Earth’s Atmosphere Dynamic Balance Meteorology. Scientific Research Publishing Inc., $110 \mathrm{p}$.

[3] Mbane Biouele, C. (2013) Hurricanes and Cyclones Kinematics and Thermodynamic Based on Clausius Clapeyron Relation Derived in 1832. International Journal of Physical Sciences, 8, 1284-1290.

[4] Mbane Biouele, C. (2009) Vertical Profiles of Winds and Electric Fields Triggered by Tropical Storms-Under the Hydrodynamic Concept of Air Particle. International Journal of Physical Sciences, 4, 242-246.

[5] Anderson, D., Anghel, A., Chau, J. and Veliz, O. (2004) Daytime Vertical ExB Drift Velocities Inferred from Ground-Based Magnetometer Observations at Low Latitudes. Space Weather, 2, S11001. http://dx.doi.org/10.1029/2004SW000095

[6] Anderson, D., Araujo Pradere, E. and Scherliess, L. (2009) Comparing Daytime Equatorial ExB Drift Velocities and TOPEX/TEC Observations Associated with the 4-Cell, Non-Migrating Tidal Structure. Annales Geophysicae, 27, 2861-2867. http://dx.doi.org/10.5194/angeo-27-2861-2009

[7] Campbell, W.H. (1997) Introduction to Geomagnetic Fields. Cambridge University Press, Cambridge.

[8] Fukushima, N. and Kamide, Y. (1973) Partial Current Models for Worldwide Geomagnetic Disturbances. Reviews of Geophysics and Space Physics, 11, 795-853. http://dx.doi.org/10.1029/RG011i004p00795

[9] Onwumechili, C.A. (1967) In: Matsushita, S. and Campbell, W.H., Eds., Physics of Geomagnetic Phenomena, 1, 425-507.

[10] Obiekezie, T.N. and Agbo, G.A. (2008) Day to Day Variability of Sq(H) Variation in the Indian Sector. JANS, 3, 81-85.

[11] Rabiu, A.B., Mamukuyomi, A.I. and Joshua, E.O. (2007) Variability of Equatorial Ionosphere Inferred from Geomagnetic Field Measurements. Bulletin of the Astronomical Society of India, 35, 607-618.

[12] Agbo, G.A., Chikwendu, A.O. and Obiekezie, T.N. (2010) Variability of Daily Horizontal Component of Geomagnetic Field Component at Low and Middle Latitudes. Indian Journal of Scientific Research, 1, 1-8.

[13] Obiekezie, T.N. and Okeke, F.N. (2009) Variations of Geomagnetic H, D and Z Field Intensities on Quiet Days at West African latitudes Moldavian. Journal of Physical Science, 8, 366-372.

[14] Obiekezie, T.N. and Obiadazie, S.C. (2013) The Variability of H Component of Geomagnetic Field at the African Sector. Physical Review \& Research International, 3, 154-160.

[15] Forbes, J.M. (1981) The Equatorial Electrojet. Reviews of Geophysics, 19, 469-504. http://dx.doi.org/10.1029/RG019i003p00469

[16] Heelis, R.A. (2004) Electrodynamics in the Low and Middle Latitude Ionosphere: A Tutorial. Journal of Atmospheric and Solar-Terrestrial Physics, 66, 825-838. http://dx.doi.org/10.1016/j.jastp.2004.01.034

[17] Rabiu, A.B., et al. (2007) Variability of Equatorial Ionosphere Inferred from Geomagnetic Field Measurements. The Bulletin of the Astronomical Society of India, 35, 607-618.

[18] Price, A.T. and Wilkins, G.A. (1963) New Methods for the Analysis of Geomagnetic Fields and Their Application to the Sq Field of 1932-3. Philosophical Transactions of the Royal Society of London, Series A, 256, 31-98.

[19] Vestine, E. (1947) The Geomagnetic Field, Its Description and Analysis. Carnegie Institution of Washington Publication, Washington DC, 580.

[20] Rabiu, A.B. (2000) Geomagnetic Field Variations at the Middle Latitudes. Unpublished PhD Thesis, University of Nigeria, Nsukka.

[21] Onwumechili, C.A. (1997) The Equatorial Electrojet. Gordon and Breach Science Publishers, Amsterdam, 610 p.

[22] Onwumechili, C.A. and Ezema, P.O. (1977) On the Course of the Geomagnetic Daily Variation in Low Latitudes. Journal of Atmospheric and Terrestrial Physics, 39, 1079-1086. http://dx.doi.org/10.1016/0021-9169(77)90016-2 